Article

\title{
Experimental Investigation and Analytical Modeling of Chloride Diffusivity of Fly Ash Concrete
}

\author{
Jian Zhang ${ }^{1}$, Xin-Zhu Zhou ${ }^{2, *}$, Jian-Jun Zheng ${ }^{2}$, Hai-Long Ye ${ }^{3 \oplus \mathbb{C}}$ and Jin Yang ${ }^{1}$ \\ 1 Jiyang College, Zhejiang Agriculture and Forestry University, Zhuji 311800, China; \\ JianZhang_zjyc@163.com (J.Z.); JinYang_jyc@163.com (J.Y.) \\ 2 School of Civil Engineering and Architecture, Zhejiang University of Technology, Hangzhou 310023, China; \\ jjzheng@zjut.edu.cn \\ 3 Department of Civil Engineering, The University of Hong Kong, Pokfulam Road, Hong Kong, China; \\ hlye@hku.hk \\ * Correspondence: xzzhou66@zjut.edu.cn
}

Received: 17 December 2019; Accepted: 10 February 2020; Published: 14 February 2020

check for updates

\begin{abstract}
Owing to its importance in the assessment of reinforced concrete structures, it is essential to determine the chloride diffusivity of fly ash concrete. This paper presents an investigation into the diffusion characteristics of chloride ions in fly ash concrete. Through experiment, the relationship between chloride diffusivity and curing age up to 1800 days is measured and the effects of curing age, water/binder ratio, aggregate volume fraction, and fly ash content (i.e., percentage of total cementitious material by mass) on chloride diffusivity are evaluated. It is found that the chloride diffusivity decreases with the increase of curing age, aggregate volume fraction, and fly ash content, but increases with the increase of water/binder ratio. In analytical modeling, an equivalent aggregate model is constructed and the equivalent interfacial transition zone (ITZ) thickness is derived analytically. With the equivalent aggregate model, three-phase fly ash concrete reduces to a two-phase composite material. By extending the Maxwell method, the chloride diffusivity of fly ash concrete is formulated. Finally, the validity of the analytical method is verified by experimental results.
\end{abstract}

Keywords: fly ash concrete; chloride diffusivity; experimental investigation; analytical method

\section{Introduction}

Reinforced concrete structures may be subjected to reinforcement corrosion when they are built in a harsh environment. As a result, some harmful species, such as chloride ions and sulfate ions, penetrate into concrete under the concentration gradient and cause corrosion of reinforcing steel bars and concrete cracking. Therefore, the chloride diffusivity of concrete plays an important role in assessing the durability of reinforced concrete structures [1,2].

To improve the durability of reinforced concrete structures, fly ash is often added into concrete as a mineral admixture, and the chloride diffusivity can be reduced significantly owing to the pozzolanic reaction of fly ash [3,4]. It has been shown that the pozzolanic reaction of fly ash occurs mainly in later curing ages from 90 to 360 days [5-7]. Such hydration characteristics can reduce the porosity and improve the pore structure of concrete for a long time [8,9], therefore making concrete increasingly denser and improving the penetration resistance against chloride ions. Poon et al. [5] demonstrated by a mercury-injection method that mixing fly ash into mortar and net cement paste can greatly reduce the porosity of the interfacial transition zone (ITZ) and the cement paste matrix. Ahmaruzzaman [10] further confirmed that the accumulation effect posed by fly ash particles on the aggregate surface and the pozzolanic reaction can make the ITZ disappear eventually. 
Much effort has been made to determine the chloride diffusivity of concrete experimentally and theoretically. Thomas et al. [11] observed from an in-situ test that, within a curing time of 28 days, the decreasing effect of fly ash incorporation on the chloride diffusivity of concrete is negligibly small. As the curing age increases, however, the decreasing effect becomes more and more significant. Zhou et al. [12] studied the relationship between chloride diffusivity of concrete and fly ash content (i.e., percentage of total cementitious material by mass) in an electrical conductivity test and concluded that adding fly ash into cement paste significantly reduces the chloride diffusivity. Oh and Jang used a non-steady-state migration test to measure the chloride diffusivity of concrete and found that, when fly ash content is less than $25 \%$, the chloride diffusivity decreases alongside an increase in fly ash content [13]. Otherwise, the opposite trend was observed. Yu and Ye [14] further studied experimentally the influence of curing age on the diffusion of chloride ions in fly ash concrete. They found from mercury intrusion porosimetry (MIP) tests that the microstructure is continuously improved during the curing period and fly ash still plays a part in enhancing the penetration resistance against chloride ions within a long duration. Moradllo et al. [15] adopted transmission X-ray microscopy and X-ray computed microtomography to investigate the in-situ diffusion of chloride ions in cement paste. Chalee et al. [16] took the water/binder ratio and the fly ash content as the experimental variables to analyze the long-term transport properties of concrete. Based on the test results, an empirical relationship was regressed between chloride diffusivity and curing age. In terms of theory, Damrongwiriyanupap et al. [17] formulated the chloride diffusivity of cement paste in terms of the porosity and the chloride diffusivity of pore solution and verified the analytical relationship with experimental results. Gu et al. [18] adopted a multi-scale model to compute the chloride diffusivity of ultra-high performance concrete and demonstrated that the numerical results slightly overestimate the experimental results. With a multi-level diffusion model, Ren et al. [19] proposed a hierarchy process for the effective prediction of the chloride diffusivity of manufactured sand mortar and to evaluate the influence of aggregate shape and limestone powder on chloride diffusivity. Based on a random walk algorithm, the chloride diffusivity of concrete was estimated [20]. Oh and Jang [13] quantified the effects of aggregate volume fraction and ITZ volume fraction on the chloride diffusivity of concrete by combining numerical methods with analytical approaches. Zheng et al. [21] proposed a differential effective medium approach to evaluate the effect of aggregate shape on the chloride diffusivity of concrete. Liu et al. [22] developed a numerical method to model the ingress of chloride ions into reconstructed concrete. Zhou et al. [12] presented an analytical approach to the chloride diffusivity of fly ash cement paste. By analyzing a short-term chloride exposure test, Zhang et al. [23] indicated that the power function can be used to describe the time-dependence of chloride diffusivity of concrete. For concrete with mineral admixtures, it is also appropriate to describe the relationship between chloride diffusivity and curing age with the power function [16]. The literature review above clearly shows that there are two limitations to the current studies. First, most experiments focus on the short-term transport properties of fly ash cement paste or concrete. Second, few theoretical models are available for estimating the chloride diffusivity of fly ash concrete. Therefore, it is necessary to investigate the long-term transport properties of fly ash concrete experimentally and theoretically.

The objective of this paper is to study the diffusion characteristics of fly ash concrete. An experiment is conducted to analyze the time dependence of chloride diffusivity and to evaluate the key influential factors. An analytical method is then presented to estimate the chloride diffusivity of fly ash concrete. Finally, the validity of the analytical method is verified with experimental results.

\section{Chloride Diffusion Test of Fly Ash Concrete}

\subsection{Materials and Methods}

This chloride diffusion test was conducted from September 2013 to December 2018. The fly ash concrete specimens were made with P.O 42.5 cement and fly ash of grade II [24]. Their chemical compositions are listed in Table 1 . The apparent density and specific surface were $2300 \mathrm{~kg} / \mathrm{m}^{3}$ and 
$295 \mathrm{~m}^{2} / \mathrm{kg}$ for the fly ash and $3150 \mathrm{~kg} / \mathrm{m}^{3}$ and $342 \mathrm{~m}^{2} / \mathrm{kg}$ for the cement, respectively. Crushed stone and river sand were selected for the coarse aggregate and fine aggregate, respectively. The aggregate gradation obeyed the Fuller curve and the aggregate size was divided into seven grades, i.e., $0.15-0.3$, $0.3-0.6,0.6-1.18,1.18-2.36,2.36-4.75,4.75-9.5$, and $9.5-16 \mathrm{~mm}$. The apparent density, water content, and water absorption were $2760 \mathrm{~kg} / \mathrm{m}^{3}, 0.48 \%$, and $0.72 \%$ for the crushed stone and $2600 \mathrm{~kg} / \mathrm{m}^{3}, 0.58 \%$, and $0.77 \%$ for the river sand, respectively. Tap water was used for mixing fly ash concrete, and a saturated $\mathrm{Ca}(\mathrm{OH})_{2}$ solution with $\mathrm{pH}$ of about 12.5 was adopted for curing the specimens to avoid the calcium leaching of fly ash concrete.

Table 1. Chemical compositions of fly ash and cement.

\begin{tabular}{ccccccccc}
\hline Material & $\mathrm{CaO}(\%)$ & $\mathrm{SiO}_{2}(\%)$ & $\mathrm{Al}_{2} \mathrm{O}_{3}(\%)$ & $\mathrm{Fe}_{2} \mathrm{O}_{3}(\%)$ & $\mathrm{MgO}(\%)$ & $\mathrm{SO}_{3}(\%)$ & $\mathrm{K}_{\mathbf{2}} \mathrm{O}(\%)$ & $\mathrm{Na}_{2} \mathrm{O}(\%)$ \\
\hline Fly ash & 5.40 & 47.00 & 26.37 & 5.23 & 0.38 & 0.85 & 0.67 & 0.61 \\
Cement & 65.31 & 21.21 & 3.88 & 3.25 & 1.12 & 0.98 & 0.57 & 0.12 \\
\hline
\end{tabular}

The water/binder ratio $(\mathrm{w} / \mathrm{b})$ of fly ash concrete was selected as 0.4 and 0.5 . For each water/binder ratio, the aggregate volume fraction $C_{a}$ was $0.55,0.65$, and 0.75 and the fly ash content $\mathrm{m}_{\mathrm{f}}$ was $0.1,0.2$, and 0.3. The mix proportions of fly ash concrete are shown in Table 2.

Table 2. Mix proportions of fly ash concrete.

\begin{tabular}{ccccc}
\hline \multirow{2}{*}{$\mathbf{w} / \mathbf{b}$} & \multicolumn{4}{c}{ Dosage of Material $\mathbf{( k g / \mathbf { m } ^ { 3 } )}$} \\
\cline { 2 - 5 } & Fly Ash & Cement & Water & Aggregate \\
\hline 0.4 & 61.7 & 555.3 & 246.8 & 1474.1 \\
0.4 & 121.5 & 485.9 & 242.9 & 1474.0 \\
0.4 & 179.4 & 418.6 & 239.2 & 1473.9 \\
0.4 & 48.0 & 432.0 & 192.0 & 1742.0 \\
0.4 & 91.9 & 367.6 & 183.8 & 1742.1 \\
0.4 & 132.3 & 308.6 & 176.3 & 1742.0 \\
0.4 & 34.3 & 308.5 & 137.1 & 2010.0 \\
0.4 & 67.5 & 269.9 & 135.0 & 2010.0 \\
0.4 & 99.7 & 232.5 & 132.9 & 2010.0 \\
0.5 & 54.3 & 488.4 & 271.4 & 1474.0 \\
0.5 & 107.0 & 428.1 & 267.6 & 1473.9 \\
0.5 & 158.3 & 369.4 & 263.9 & 1474.0 \\
0.5 & 42.2 & 379.9 & 211.0 & 1742.0 \\
0.5 & 83.2 & 333.0 & 208.1 & 1741.9 \\
0.5 & 123.1 & 287.3 & 205.2 & 1742.0 \\
0.5 & 30.1 & 271.3 & 150.7 & 2010.0 \\
0.5 & 59.5 & 237.8 & 148.6 & 2010.0 \\
0.5 & 88.0 & 205.2 & 146.6 & 2010.0 \\
\hline
\end{tabular}

The curing age $\mathrm{t}$ was set as $28,60,120,240,540,720,1260$, and 1800 days. Concrete cylinders with dimensions of $\Phi 100 \mathrm{~mm} \times 100 \mathrm{~mm}$ were cast. To obtain a representative mean, three identical cylinders were made for a given mix proportion and age. After 28 days of standard curing, concrete specimens with sizes of $\Phi 100 \mathrm{~mm} \times 50 \mathrm{~mm}$ were formed by cutting the two edges of the concrete cylinders and again immersed in the saturated $\mathrm{Ca}(\mathrm{OH})_{2}$ solution at a curing temperature of $20 \pm 2{ }^{\circ} \mathrm{C}$. During the curing period, the saturated $\mathrm{Ca}(\mathrm{OH})_{2}$ solution was replaced monthly. Finally, the chloride diffusivity $\mathrm{D}_{\mathrm{cf}}$ was measured by the electrical conductivity method [25]. The schematic of the test device is shown in Figure 1. 


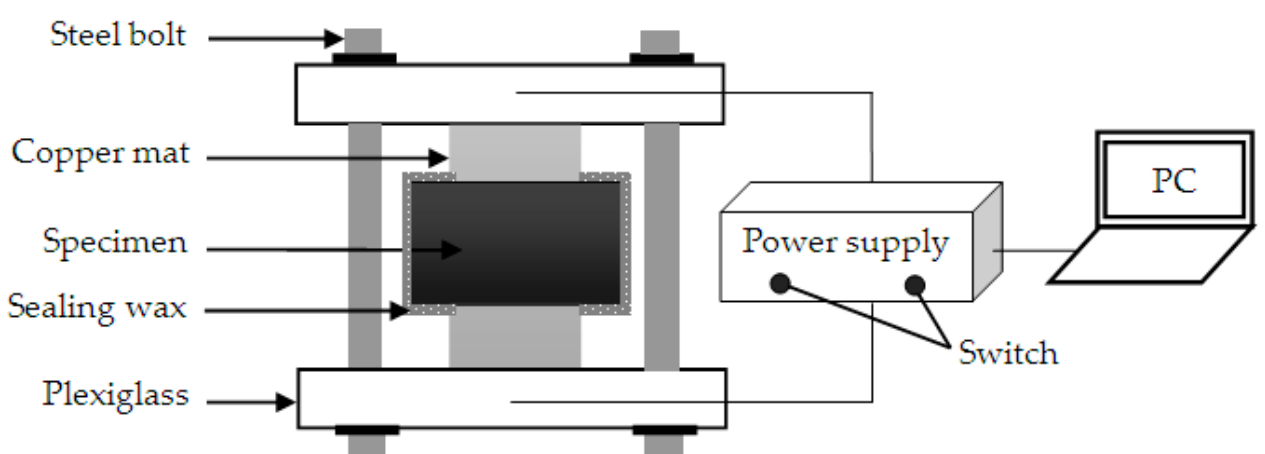

Figure 1. Schematic of test device.

\subsection{Experimental Results and Discussions}

The effects of $w / b, C_{a}, m_{f}$, and $t$ on $D_{c f}$ are shown in Figures 2 and 3 . It can be seen from Figures 2 and 3 that $D_{c f}$ increases with the increase of $w / b$. The reason for this is that a larger water/binder ratio results in a larger porosity. $D_{c f}$ decreases almost linearly with increasing $C_{a}$ for a given $w / b, C_{a}$, and $t$ owing to the dilute and tortuous effects of aggregates [26]. The optimum dosage of fly ash is 0.3 . When $\mathrm{w} / \mathrm{b}=0.4$ and $\mathrm{t}=28,120,540$, and 1800 days, $\mathrm{D}_{\mathrm{cf}}$ at $\mathrm{m}_{\mathrm{f}}=0.3$ is smaller than that at $\mathrm{m}_{\mathrm{f}}=0.1$ by $33.2 \%, 36.4 \%, 48.1 \%$, and $69.7 \%$ for $\mathrm{C}_{\mathrm{a}}=0.55 ;$ by $22.6 \%, 26.9 \%, 49.0 \%$, and $66.1 \%$ for $\mathrm{C}_{\mathrm{a}}=0.65$; and by $33.4 \%, 36.7 \%, 38.7 \%$, and $54.5 \%$ for $\mathrm{C}_{\mathrm{a}}=0.75$, respectively. Similarly, when $\mathrm{w} / \mathrm{b}=0.5$ and $\mathrm{t}$ is $28,120,540$, and 1800 days, $\mathrm{D}_{\mathrm{cf}}$ at $\mathrm{m}_{\mathrm{f}}=0.3$ is smaller than that at $\mathrm{m}_{\mathrm{f}}=0.1$ by $28.2 \%, 37.1 \%, 37.4 \%$, and $46.4 \%$ for $\mathrm{C}_{\mathrm{a}}=0.55$; by $22.6 \%, 36.2 \%, 46.7 \%$, and $62.8 \%$ for $\mathrm{C}_{\mathrm{a}}=0.65$; and by $33.0 \%, 38.3 \%, 52.4 \%$, and $56.9 \%$ for $C_{a}=0.75$, respectively, which indicates that $D_{c f}$ decreases with the increase of $\mathrm{m}_{\mathrm{f}}$. This can be explained as follows. On the one hand, the micro-aggregate effect of fly ash improves the density of fly ash cement paste and the pozzolanic products are more compact than calcium-silicate-hydrates formed from cement hydration [27]. On the other hand, the cations induced by the pozzolanic hydration reaction are distributed in the pore solution and cause the pore walls to be charged negatively, thus hindering the diffusion of chloride ions [28,29].

It can also be seen from Figures 2 and 3 that the chloride diffusivity of fly ash concrete decreases quickly with increasing $\mathrm{t}$ for a given $\mathrm{t}$ smaller than 540 days, but almost remains unchanged for a given $\mathrm{t}$ larger than 540 days. When $\mathrm{w} / \mathrm{b}=0.4$ and $\mathrm{m}_{\mathrm{f}}=0.1,0.2$, and $0.3, \mathrm{D}_{\mathrm{cf}}$ at $\mathrm{t}=540$ days is smaller than that at $\mathrm{t}=28$ days by $71.7 \%, 76.0 \%$, and $78.1 \%$ for $\mathrm{C}_{\mathrm{a}}=0.55 ;$ by $71.0 \%, 80.9 \%$, and $81.8 \%$ for $\mathrm{C}_{\mathrm{a}}=0.65$; and by $80.0 \%, 82.2 \%$, and $81.7 \%$ for $\mathrm{C}_{\mathrm{a}}=0.75$, respectively. When $\mathrm{w} / \mathrm{b}=0.5$ and $\mathrm{m}_{\mathrm{f}}=0.1,0.2$, and $0.3, \mathrm{D}_{\text {cf }}$ at $\mathrm{t}=540$ days is smaller than that at $\mathrm{t}=28$ days by $84.6 \%, 85.2 \%$, and $86.6 \%$ for $\mathrm{C}_{\mathrm{a}}=0.55$; by $79.2 \%, 80.9 \%$, and $85.7 \%$ for $C_{a}=0.65$; and by $78.1 \%, 82.2 \%$, and $84.5 \%$ for $C_{a}=0.75$, respectively. This is due to the fact that the hydration of fly ash exhibits a time-delay characteristic [5]. 


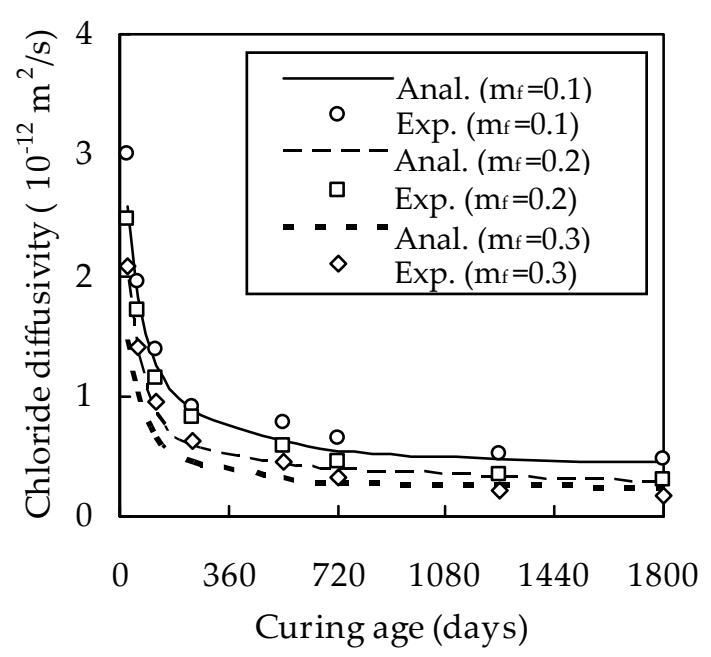

(a) $\mathrm{C}_{\mathrm{a}}=0.55$

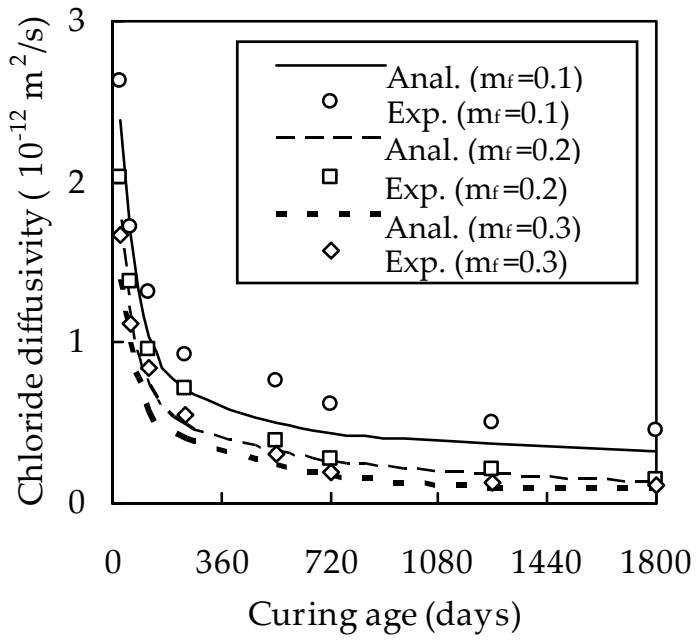

(b) $\mathrm{C}_{\mathrm{a}}=0.65$

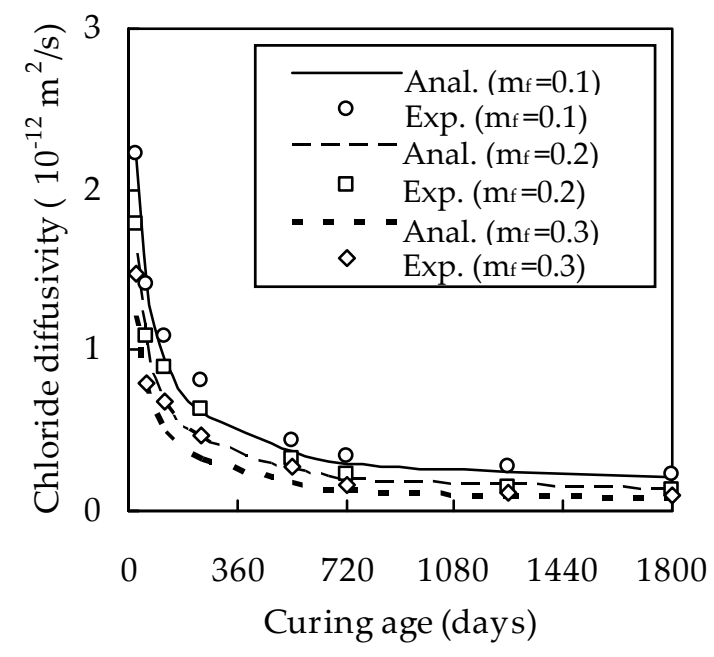

(c) $\mathrm{C}_{\mathrm{a}}=0.75$

Figure 2. Variation of $\mathrm{D}_{\mathrm{cf}}$ with $\mathrm{t}$ for $\mathrm{w} / \mathrm{b}=0.4$.

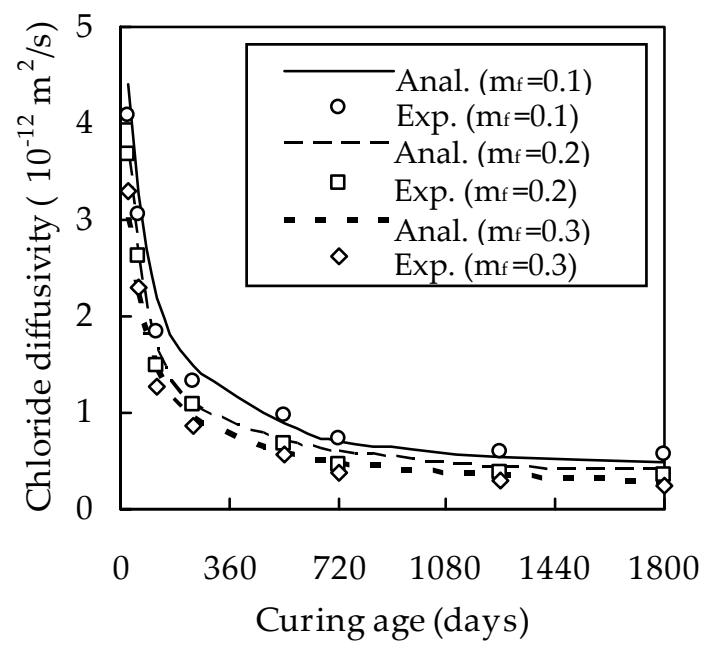

(a) $\mathrm{C}_{\mathrm{a}}=0.55$

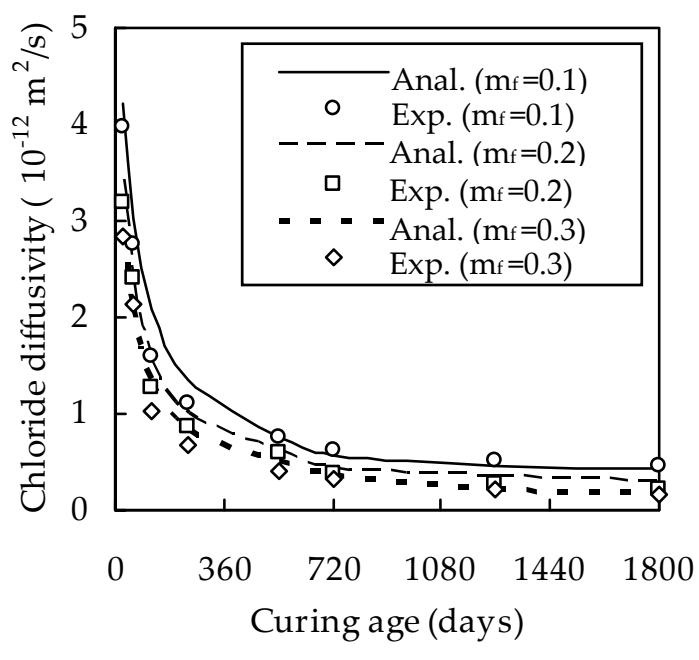

(b) $\mathrm{C}_{\mathrm{a}}=0.65$

Figure 3. Cont. 


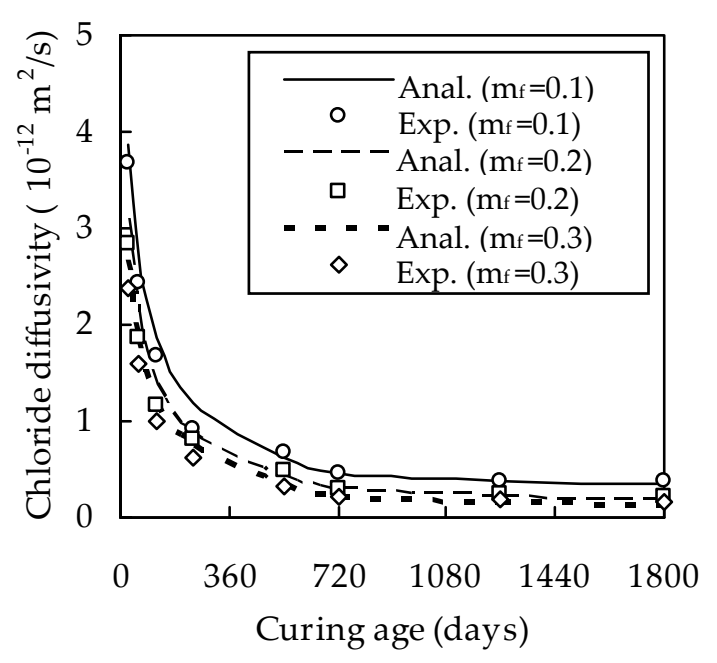

(c) $\mathrm{Ca}=0.75$

Figure 3. Variation of $D_{c f}$ with $t$ for $w / b=0.5$.

\section{Chloride Diffusivity of Fly Ash Concrete}

In modeling fly ash concrete, aggregates are considered to be spherical. An ITZ with low strength and high porosity is formed between aggregates and the cement paste matrix due to the low packing efficiency of cement particles near aggregates. It was experimentally confirmed that addition of fly ash results in a denser and stronger ITZ, possibly due to the filling effect of small fly ash particles [30,31]. However, the chloride diffusivity of ITZ is still much larger than that of fly ash cement paste [31]. Therefore, it is appropriate to model the ITZ as an independent phase. At present, a more consistent point of view is accepted from the experimental results obtained by Scrivener and Nemati [32] based on electron microscopy, i.e., the ITZ thickness is almost independent of the aggregate size. Thus, fly ash concrete is composed of spherical aggregates, ITZs with equal thickness, and a fly ash cement paste. The aggregate size $D$ is divided into $N$ grades $\left[D_{j}, D_{j+1}\right](j=1,2, \ldots, N)$ according to sieving analyses. If the cumulative distribution function for the aggregate is approximately linear piece-wise in each sub-domain, the probability density function $\mathrm{p}_{\mathrm{N}}(\mathrm{D})$ and the cumulative distribution function $\mathrm{P}_{\mathrm{N}}(\mathrm{D})$ in terms of the number of aggregates are [33]

$$
\begin{gathered}
\mathrm{p}_{\mathrm{N}}(\mathrm{D})=\sum_{j=1}^{\mathrm{N}} \frac{6\left[\mathrm{P}_{\mathrm{V}}\left(\mathrm{D}_{\mathrm{j}+1}\right)-\mathrm{P}_{\mathrm{V}}\left(\mathrm{D}_{\mathrm{j}}\right)\right]}{\mu \pi \mathrm{N}_{\mathrm{V}}\left(\mathrm{D}_{\mathrm{j}+1}-\mathrm{D}_{\mathrm{j}}\right) \mathrm{D}^{3}}\left[\mathrm{H}\left(\mathrm{D}-\mathrm{D}_{\mathrm{j}}\right)-\mathrm{H}\left(\mathrm{D}-\mathrm{D}_{\mathrm{j}+1}\right)\right] \\
\mathrm{P}_{\mathrm{N}}(\mathrm{D})=\sum_{j=1}^{\mathrm{k}-1} \frac{3\left[\mathrm{P}_{\mathrm{V}}\left(\mathrm{D}_{\mathrm{j}+1}\right)-\mathrm{P}_{\mathrm{V}}\left(\mathrm{D}_{\mathrm{j}}\right)\right]\left(\mathrm{D}_{\mathrm{j}}+\mathrm{D}_{\mathrm{j}+1}\right)}{\mu \pi \mathrm{N}_{\mathrm{V}} \mathrm{D}_{\mathrm{j}}^{2} \mathrm{D}_{\mathrm{j}+1}^{2}}+\frac{3\left[\mathrm{P}_{\mathrm{V}}\left(\mathrm{D}_{\mathrm{k}+1}\right)-\mathrm{P}_{\mathrm{V}}\left(\mathrm{D}_{\mathrm{k}}\right)\right]\left(\mathrm{D}^{2}-\mathrm{D}_{\mathrm{k}}^{2}\right)}{\mu \pi \mathrm{N}_{\mathrm{V}}\left(\mathrm{D}_{\mathrm{k}+1}^{2}-\mathrm{D}_{\mathrm{k}}^{2}\right) \mathrm{D}_{\mathrm{k}}^{2} \mathrm{D}^{2}}
\end{gathered}
$$

where $D_{k} \leq D \leq D_{k+1}$ and the Heaviside step function $H(x)$ is defined as

$$
\mathrm{H}(\mathrm{x})=\left\{\begin{array}{cc}
1, & \mathrm{x}>0 \\
0.5, & \mathrm{x}=0 \\
0, & \mathrm{x}<0
\end{array}\right.
$$

The number of aggregates per unit volume of aggregate, $\mathrm{N}_{\mathrm{V}}$, is obtained as

$$
N_{V}=\sum_{j=1}^{N} \frac{3\left(D_{j}+D_{j+1}\right)\left[P_{V}\left(D_{j+1}\right)-P_{V}\left(D_{j}\right)\right]}{\mu \pi D_{j}^{2} D_{j+1}^{2}} .
$$


It is well known that ITZs will overlap when spherical aggregates are randomly distributed in concrete and, the larger the aggregate volume fraction is, the higher the overlap degree of ITZ will be. In order to consider the ITZ overlap and to construct a two-phase composite material model, composed of equivalent spherical aggregates and a fly ash cement paste, the following three-step scheme is adopted to determine the equivalent ITZ thickness.

1. Calculation of ITZ volume fraction $f_{i}$ without ITZ overlap effect. If the equivalent ITZ thickness is denoted as $h_{e q}$, the ITZ volume for a single spherical aggregate is given by

$$
\mathrm{V}_{\mathrm{i}}=\frac{\pi}{6}\left[\left(\mathrm{D}+2 \mathrm{~h}_{\mathrm{eq}}\right)^{3}-\mathrm{D}^{3}\right]
$$

Thus, the ITZ volume fraction $\mathrm{f}_{\mathrm{i}}$ is equal to

where $f_{a}$ is the aggregate volume fraction, and $\langle D\rangle$ and $\left\langle D^{2}\right\rangle$ are the first and second moments of area of $\mathrm{p}_{\mathrm{N}}(\mathrm{d})$, respectively. For any integer $\mathrm{k},\left\langle\mathrm{D}^{\mathrm{k}}\right\rangle$ is defined as

$$
\left\langle\mathrm{D}^{\mathrm{k}}\right\rangle=\int_{\mathrm{D}_{1}}^{\mathrm{D}_{\mathrm{N}+1}} \mathrm{D}^{\mathrm{k}} \mathrm{p}_{\mathrm{N}}(\mathrm{D}) \mathrm{dD}
$$

Substitution of Equation (1) into Equation (7) yields

$$
\left\langle D^{k}\right\rangle=\left\{\begin{array}{l}
\sum_{j=1}^{N} \frac{6\left[P_{V}\left(D_{j+1}\right)-P_{V}\left(D_{j}\right)\right] \ln \left(D_{j+1} / D_{j}\right)}{\pi \mu N_{V}\left(D_{j+1}-D_{j}\right)}, k=2 \\
\sum_{j=1}^{N} \frac{6\left[P_{V}\left(D_{j+1}\right)-P_{V}\left(D_{j}\right)\right]\left(D_{j+1}^{k-2}-D_{j}^{k-2}\right)}{(k-2) \pi \mu N_{V}\left(D_{j+1}-D_{j}\right)}, k \neq 2
\end{array}\right.
$$

2. Calculation of ITZ volume fraction $f_{i}$ with ITZ overlap effect. Based on the geometric statistical theory of composite materials, Lu and Torquato [34] proposed a method for calculating the ITZ volume fraction, in which the overlap between adjacent ITZs is taken into account. According to their theory, $\mathrm{f}_{\mathrm{i}}$ is given by

$$
\mathrm{f}_{\mathrm{i}}=\left(1-\mathrm{f}_{\mathrm{a}}\right)\left[1-\exp \left(-\mathrm{t}_{1} \mathrm{~h}-\mathrm{t}_{2} \mathrm{~h}^{2}-\mathrm{t}_{3} \mathrm{~h}^{3}\right)\right]
$$

where $h$ is the practical ITZ thickness and $t_{1}, t_{2}$, and $t_{3}$ are expressed in terms of $f_{a}$ and $\left\langle D^{k}\right\rangle$ as

$$
\begin{gathered}
\mathrm{t}_{1}=\frac{6 \mathrm{f}_{\mathrm{a}}\left\langle\mathrm{D}^{2}\right\rangle}{\left(1-\mathrm{f}_{\mathrm{a}}\right)\left\langle\mathrm{D}^{3}\right\rangle} \\
\mathrm{t}_{2}=\frac{12 \mathrm{f}_{\mathrm{a}}\langle\mathrm{D}\rangle}{\left(1-\mathrm{f}_{\mathrm{a}}\right)\left\langle\mathrm{D}^{3}\right\rangle}+\frac{18 \mathrm{f}_{\mathrm{a}}^{2}\left\langle\mathrm{D}^{2}\right\rangle^{2}}{\left(1-\mathrm{f}_{\mathrm{a}}\right)^{2}\left\langle\mathrm{D}^{3}\right\rangle^{2}} \\
\mathrm{t}_{3}=\frac{8 \mathrm{f}_{\mathrm{a}}}{\left(1-\mathrm{f}_{\mathrm{a}}\right)\left\langle\mathrm{D}^{3}\right\rangle}+\frac{24 \mathrm{f}_{\mathrm{a}}^{2}\langle\mathrm{D}\rangle\left\langle\mathrm{D}^{2}\right\rangle}{\left(1-\mathrm{f}_{\mathrm{a}}\right)^{2}\left\langle\mathrm{D}^{3}\right\rangle^{2}}+\frac{8 \mathrm{f}_{\mathrm{a}}^{3}\left\langle\mathrm{D}^{2}\right\rangle^{3} \lambda}{\left(1-\mathrm{f}_{\mathrm{a}}\right)^{3}\left\langle\mathrm{D}^{3}\right\rangle^{3}}
\end{gathered}
$$

3. Determination of equivalent ITZ thickness $h_{\text {eq }}$. From Equations (6) and (9), $h_{\text {eq }}$ can be obtained as

$$
h_{\mathrm{eq}}=\sqrt[3]{-\frac{\mathrm{q}}{2}+\sqrt{\frac{\mathrm{q}^{2}}{4}+\frac{\mathrm{p}^{3}}{27}}}+\sqrt[3]{-\frac{\mathrm{q}}{2}-\sqrt{\frac{\mathrm{q}^{2}}{4}+\frac{\mathrm{p}^{3}}{27}}}-\langle\mathrm{D}\rangle
$$

where $\mathrm{p}$ and $\mathrm{q}$ are defined as

$$
\mathrm{p}=3\left(\left\langle\mathrm{D}^{2}\right\rangle-\langle\mathrm{D}\rangle^{2}\right) / 4
$$




$$
\mathrm{q}=\frac{\langle\mathrm{D}\rangle^{3}}{4}-\frac{3\langle\mathrm{D}\rangle\left\langle\mathrm{D}^{2}\right\rangle}{8}-\frac{3 \mathrm{f}_{\mathrm{i}}}{4 \pi \mathrm{N}_{\mathrm{V}} \mathrm{f}_{\mathrm{a}}}
$$

As can be seen from Equations (13) to (15), the main factors that influence $h_{e q}$ include $f_{a}, p_{N}(D)$, and $h$.

With $h_{\text {eq }}$ known, the chloride diffusivity of an equivalent spherical aggregate, composed of a spherical aggregate and an equivalent ITZ, is given by [35]

$$
D_{\text {ea }}=D_{i}+D_{i}\left[\left(\frac{V_{a}}{V_{a}+V_{i}} \cdot \frac{D_{a}-D_{i}}{D_{i}+\left(D_{a}-D_{i}\right) / 3}\right)^{-1}-\frac{1}{3}\right]^{-1}
$$

where $D_{a}$ and $D_{i}$ are the chloride diffusivities of aggregate and ITZ and $V_{a}$ and $V_{i}$ are the volumes of the aggregate and the ITZ, respectively. It is obvious that

$$
\begin{gathered}
\mathrm{V}_{\mathrm{a}}=\frac{\pi \mathrm{D}^{3}}{6} \\
\mathrm{~V}_{\mathrm{i}}=\frac{\pi\left[\left(\mathrm{D}+2 \mathrm{~h}_{\mathrm{eq}}\right)^{3}-\mathrm{D}^{3}\right]}{6} .
\end{gathered}
$$

Since the density of aggregate is much higher than those of ITZ and bulk paste, the chloride diffusivity $\mathrm{D}_{\mathrm{a}}$ can be assumed to be zero. Thus, Equation (16) reduces to

$$
\mathrm{D}_{\mathrm{ea}}=\frac{2 \mathrm{~V}_{\mathrm{i}}}{3 \mathrm{~V}_{\mathrm{a}}+2 \mathrm{~V}_{\mathrm{i}}} \mathrm{D}_{\mathrm{i}}
$$

With the equivalent aggregate model, three-phase fly ash concrete can be reduced to a two-phase composite material, composed of equivalent aggregates of various sizes and chloride diffusivities encompassed by a fly ash cement paste of chloride diffusivity $\mathrm{D}_{\mathrm{f}}$, as shown in Figure 4 . According to the Maxwell method, the chloride diffusivity of a two-phase composite material is given by

$$
\frac{D_{e}-D_{1}}{D_{e}+2 D_{1}}=\varphi_{2} \frac{D_{2}-D_{1}}{D_{2}+2 D_{1}}
$$

where $D_{e}, D_{1}$, and $D_{2}$ are the chloride diffusivities of the effective medium, phase 1 , and phase 2, respectively, and $\varphi_{2}$ is the volume fraction of phase 2. By extending the Maxwell method to the fly ash concrete with $\mathrm{N}$-type aggregates, the chloride diffusivity is given by

$$
\frac{D_{c f}-D_{f}}{D_{c f}+2 D_{f}}=\sum_{j=1}^{N} \frac{\left(D_{e a, j}-D_{f}\right) \varphi_{j}}{D_{e a, j}+2 D_{f}}
$$

where $\varphi_{\mathrm{j}}$ is defined as

$$
\varphi_{j}=\frac{f_{a} d_{e a, j}^{3}}{\sum_{j=1}^{N} d_{e a, j}^{3}}
$$

with $D_{f}$ and $D_{e a, j}$ being the chloride diffusivities of the fly ash cement paste and the $j$-th equivalent aggregate, and $\mathrm{d}_{\mathrm{ea}, \mathrm{j}}$ and $\varphi_{\mathrm{j}}$ being the diameter and volume fraction of the $\mathrm{j}$-th equivalent aggregate, respectively.

Finally, solving Equation (21) gives the chloride diffusivity of fly ash concrete

$$
D_{c f}=D_{f} \frac{1+2 \sum_{j=1}^{N} \varphi_{j} \frac{D_{e a, j}-D_{f}}{D_{e a, j}+2 D_{f}}}{1-\sum_{j=1}^{N} \varphi_{j} \frac{D_{e a, j}-D_{f}}{D_{e a, j}+2 D_{f}}} .
$$




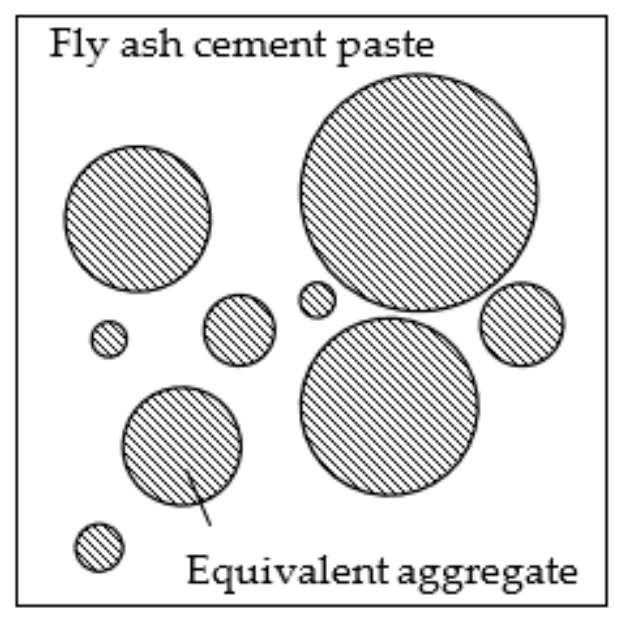

Figure 4. Two-phase fly ash concrete composed of fly ash cement paste and equivalent aggregates.

\section{Experimental Verification and Discussions}

Using the analytical method proposed by Zhou et al. [12], the chloride diffusivity $\mathrm{D}_{\mathrm{f}}$ of fly ash cement paste can be estimated. To evaluate the chloride diffusivity of the equivalent aggregate from Equation (19), the ITZ chloride diffusivity $D_{i}$ needs to be known beforehand. Since it is still difficult to measure the ITZ chloride diffusivity directly through testing, experimental calibration is conducted to determine the ratio $D_{i} / D_{b}$. For this purpose, the experimental results for $w / b=0.5$ and $C_{a}=0.55,0.65$, and 0.75 are selected. As for the ITZ thickness, available experimental results do not achieve a consistent conclusion. Qian et al. [36] indicated that addition of fly ash decreases the ITZ thickness by 37\%. However, other studies showed that the effect of fly ash on the ITZ thickness is insignificant $[30,37,38]$. In view of this, the ITZ thickness in fly ash concrete is assumed to be similar to that in normal concrete as a preliminary study. Since the ITZ thickness is usually in the range of 0.01 to $0.05 \mathrm{~mm}$ for normal concrete [39], $h$ is taken as $0.03 \mathrm{~mm}$. Thus, the ratio of $\mathrm{D}_{\mathrm{i}} / \mathrm{D}_{\mathrm{b}}$ at $\mathrm{t}=28,60,120,540$, and 1800 days is back-calculated as $10.5,10.8,8.4,5.08$, and 1.8 for $\mathrm{m}_{\mathrm{f}}=0.1 ; 11.3,11.7,8.1,2.86$, and 1.35 for $\mathrm{m}_{\mathrm{f}}=0.2$; and $12.6,10.6,9.47,2.94$, and 1.43 for $m_{f}=0.3$, respectively. It is seen that $D_{i} / D_{b}$ is seldom influenced by the fly ash content but decreases with the increase of $t$, which agrees well with the results of Bentz [40]. The average ratio of $D_{i} / D_{b}$ at $m_{f}=0.1,0.2$, and 0.3 is equal to $11.46,11.04,8.65,3.62$, and 1.53 for $t=28$, $60,120,540$, and 1800 days, respectively. Through regression analysis, $\mathrm{D}_{\mathrm{i}} / \mathrm{D}_{\mathrm{b}}$ can be expressed as

$$
\mathrm{D}_{\mathrm{i}} / \mathrm{D}_{\mathrm{b}}=43 \mathrm{t}^{-0.366}
$$

with a correlation coefficient of 0.912 . Furthermore, when $\mathrm{m}_{\mathrm{f}}=0.1,0.2$, and 0.3 , the correlation coefficient between the analytical method and the experimental results is calculated as $0.997,0.998$, and 0.996 for $C_{a}=0.55 ; 0.993,0.995$, and 0.994 for $C_{a}=0.65$; and $0.996,0.998$, and 0.998 for $C_{a}=0.75$, respectively.

With $\mathrm{D}_{\mathrm{i}} / \mathrm{D}_{\mathrm{b}}$ known, the chloride diffusivity of fly ash concrete can be evaluated for $\mathrm{w} / \mathrm{b}=0.4$. The results are shown in Figure 2, which demonstrates that the analytical method is in good agreement with the experimental results. When $\mathrm{m}_{\mathrm{f}}=0.1,0.2$, and 0.3 , the correlation coefficient between them is $0.986,0.992$, and 0.997 for $C_{a}=0.55 ; 0.979,0.989$, and 0.992 for $C_{a}=0.65$; and $0.993,0.985$, and 0.982 for $\mathrm{C}_{\mathrm{a}}=0.75$, respectively. Therefore, the validity of the analytical method is verified.

To further validate the analytical method, the test results of Yang and Su [41] were selected. In their test, an ordinary Portland cement of type ASTM I was used and the water/binder ratio was 0.4. The aggregate volume fraction was $0,0.1,0.2,0.3$, and 0.4 , and $10 \%$ and $20 \%$ of cement by mass was replaced by fly ash or slag. The maximum and minimum aggregate diameters were 9.5 and $0.15 \mathrm{~mm}$, respectively. For an aggregate grade at $0.15-0.3,0.3-0.6,0.6-1.18,1.18-2.36,2.36-4.75,4.75-9.5$, and $9.5-16 \mathrm{~mm}$, the volume fraction was $2.83 \%, 8.57 \%, 28.9 \%, 27.8 \%, 23.5 \%, 8.1 \%$, and $0.3 \%$, respectively. 
The specimens were cast at room temperature. After $24 \mathrm{~h}$ of casting, they were taken out of molds and immediately immersed in a water tank with a curing temperature of $23^{\circ} \mathrm{C}$. After 12 months, the chloride diffusivity was measured by a migration method. The test results are shown in Figure 5 . As in the last example, $\mathrm{h}=0.03 \mathrm{~mm}$. The chloride diffusivity of cement paste is equal to $2.03 \times 10^{-12} \mathrm{~m}^{2} / \mathrm{s}$ and $D_{i}$ is calibrated from the chloride diffusivity of concrete, i.e., $8.05 \times 10^{-12} \mathrm{~m}^{2} / \mathrm{s}$, measured at $C_{a}=0.4$, as $1.34 \times 10^{-12} \mathrm{~m}^{2} / \mathrm{s}$. With these parameters, $D_{c f}$ with different $C_{a}$ can be calculated by the proposed analytical method; the results are shown in Figure 5. It can be seen from Figure 5 that the analytical method agrees well with the experimental results, with a correlation coefficient of 0.996 . Therefore, the validity of the analytical method is further verified.

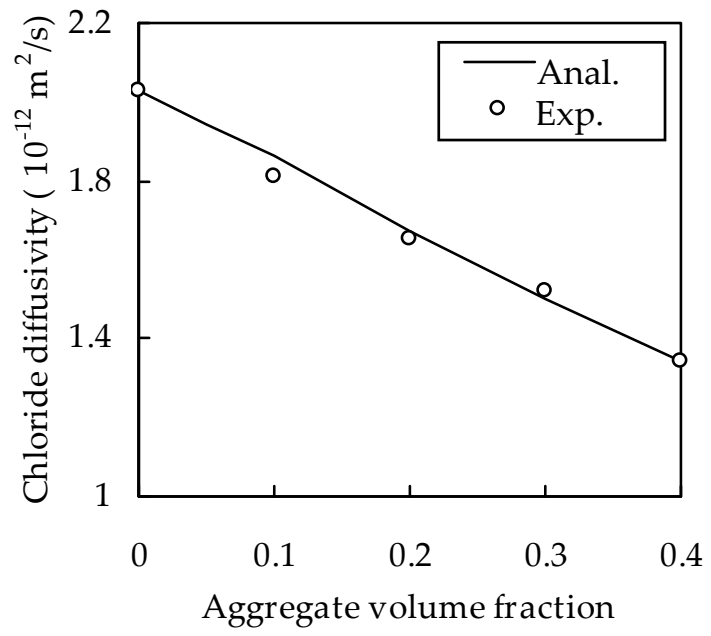

Figure 5. Comparison with experimental results of Yang and Su [41].

Although the proposed analytical method was preliminarily verified by the experimental results, more chloride diffusion tests of fly ash concrete and microstructural experiments need to be conducted to further validate the analytical method. Especially, the effects of fly ash content and water/binder ratio on the thickness, porosity, and chloride diffusivity of ITZ need to be investigated in future studies.

\section{Conclusions}

The chloride diffusivity of fly ash concrete has been measured through experiment and estimated based on the equivalent aggregate model and the generalized Maxwell method. The main conclusions of this study are as follows:

1. From the test results, it has been found that the chloride diffusivity of fly ash concrete decreases almost linearly with an increase in aggregate volume fraction. The optimum fly ash content is 0.3 . The chloride diffusivity exhibits an evidently decreasing trend for a given curing time within 540 days, but almost remains unchanged for a given curing time from 540 to 1800 days.

2. An equivalent spherical aggregate model has been proposed and the equivalent ITZ thickness has been derived analytically. The main influential factors on the equivalent ITZ thickness include the aggregate gradation, the aggregate volume fraction, and the practical ITZ thickness. The chloride diffusivity of fly ash concrete has been estimated by the analytical method and verified against experimental results.

Author Contributions: Conceptualization, J.Z., X.-Z.Z., J.-J.Z. and H.-L.Y.; methodology, J.Z and J.-J.Z. and X.-Z.Z.; software, J.Z.; validation, J.Z.; formal analysis, J.Y., H.-L.Y. and J.Z.; investigation, J.Z., X.-Z.Z. and H.-L.Y.; writing and editing, J.Z., X.-Z.Z. and J.-J.Z.; visualization, J.Z. and H.-L.Y.; project administration, J.Z. and X.-Z.Z.; funding acquisition, J.Z., X.-Z.Z. and J.-J.Z. All authors have read and agreed to the published version of the manuscript.

Funding: This research was funded by the Talent Project of Jiyang College of Zhejiang Agriculture and Forestry University, grant numbers RQ1911B06 and the National Natural Science Foundation, grant numbers 51978619, 51878615, and 51779227, of the People's Republic of China. 
Conflicts of Interest: The authors declare no conflicts of interest.

\section{References}

1. Kurumisawa, K.; Nawa, T.; Owada, H. Prediction of the diffusivity of cement-based materials using a three-dimensional spatial distribution model. Cem. Concr. Compos. 2012, 34, 408-418. [CrossRef]

2. Zheng, J.J.; Zhang, J.; Zhou, X.Z.; Wang, X.R. A numerical method for predicting the chloride diffusivity of mature cement paste. J. Mater. Civ. Eng. 2019, 31, 04019080. [CrossRef]

3. Papadakis, V.G. Effect of fly ash on Portland cement systems: Part I. low-calcium fly ash. Cem. Concr. Res. 1999, 29, 1727-1736. [CrossRef]

4. Papadakis, V.G. Effect of fly ash on Portland cement systems: Part II, high-calcium fly ash. Cem. Concr. Res. 2000, 30, 1647-1654. [CrossRef]

5. Poon, C.S.; Lam, L.; Wong, Y.L. Study on high strength concrete prepared with large volumes of low calcium fly ash. Cem. Concr. Res. 2000, 30, 447-455. [CrossRef]

6. Lam, L.; Wong, Y.L.; Poon, C.S. Degree of hydration and gel/space ratio of high-volume fly ash/cement systems. Cem. Concr. Res. 2000, 30, 747-756. [CrossRef]

7. Pastor, J.L.; Ortega, J.M.; Flor, M.; López, M.P.; Sánchez, I.; Climent, M.A. Microstructure and durability of fly ash cement grouts for micropiles. Constr. Build. Mater. 2016, 117, 47-57. [CrossRef]

8. Yio, M.H.N.; Wong, H.S.; Buenfeld, N. 3D pore structure and mass transport properties of blended cementitious materials. Cem. Concr. Res. 2019, 117, 23-37. [CrossRef]

9. Coppola, L.; Coffetti, D.; Crotti, E. Plain and ultrafine fly ashes mortars for environmentally friendly construction materials. Sustainability 2018, 10, 874. [CrossRef]

10. Ahmaruzzaman, M. A review on the utilization of fly ash. Prog. Energ. Combust. 2010, 36, 327-363. [CrossRef]

11. Thomas, M.D.A.; Shehata, M.H.; Shashiprakash, S.G.; Hopkins, D.S.; Cail, K. Use of ternary cementitious systems containing silica fume and fly ash in concrete. Cem. Concr. Res. 1999, 29, 1207-1214. [CrossRef]

12. Zhou, H.; Zhou, X.Z.; Zhang, J.; Zheng, J.J. Experimental investigation and theoretical estimate of the chloride diffusion coefficient of mature fly ash cement paste. Materials 2019, 12, 811. [CrossRef] [PubMed]

13. Oh, B.H.; Jang, S.Y. Prediction of diffusivity of concrete based on simple analytic equations. Cem. Concr. Res. 2004, 34, 463-480. [CrossRef]

14. Yu, Z.Q.; Ye, G. New perspective of service life prediction of fly ash concrete. Constr. Build. Mater. 2013, 48, 764-771. [CrossRef]

15. Moradllo, M.K.; Hu, Q.N.; Ley, M.T. Using X-ray imaging to investigate in-situ ion diffusion in cementitious materials. Constr. Build. Mater. 2017, 136, 88-98. [CrossRef]

16. Chalee, W.; Jaturapitakkul, C.; Chindaprasirt, P. Predicting the chloride penetration of fly ash concrete in seawater. Mar. Struct. 2009, 22, 341-353. [CrossRef]

17. Damrongwiriyanupap, N.; Scheiner, S.; Pichler, B.; Hellmich, C. Self-consistent channel approach for upscaling chloride diffusivity in cement pastes. Transp. Porous Med. 2017, 118, 495-518. [CrossRef]

18. Gu, C.P.; Ye, G.; Wang, Q.N.; Sun, W. Modeling of the chloride diffusivity of ultra-high performance concrete with a multi-scale scheme. Model. Simul. Mater. Sci. Eng. 2019, 27, 055002. [CrossRef]

19. Ren, Q.; De Schutter, G.; Jiang, Z.W.; Chen, Q. Multi-level diffusion model for manufactured sand mortar considering particle shape and limestone powder effects. Constr. Build. Mater. 2019, 207, 218-227. [CrossRef]

20. Zheng, J.J.; Zhang, J.; Zhou, X.Z.; Song, W.B. A numerical algorithm for evaluating the chloride diffusion coefficient of concrete with crushed aggregates. Constr. Build. Mater. 2018, 171, 977-983. [CrossRef]

21. Zheng, J.J.; Zhou, X.Z.; Xing, H.Y.; Jin, X.Y. Differential effective medium theory for the chloride diffusivity of concrete. ACI Mater. J. 2015, 112, 3-10. [CrossRef]

22. Liu, Q.F.; Easterbrook, D.; Yang, J.; Li, L.Y. A three-phase, multi-component ionic transport model for simulation of chloride penetration in concrete. Eng. Struct. 2015, 86, 122-133. [CrossRef]

23. Zhang, J.Z.; Zheng, Y.Y.; Wang, J.D.; Zhang, Y.R.; Gao, Y.H. Chloride transport in concrete under flexural loads in a tidal environment. J. Mater. Civ. Eng. 2018, 30, 04018285. [CrossRef]

24. Gao, Y.L.; Cheng, L.; Gao, Z.M.; Guo, S.Y. Effects of different mineral admixtures on carbonation resistance of lightweight aggregate concrete. Constr. Build. Mater. 2013, 43, 506-510. [CrossRef]

25. Lu, X.Y. Application of the Nernst-Einstein equation to concrete. Cem. Concr. Res. 1997, 27, $293-302$. [CrossRef] 
26. Caré, S. Influence of aggregates on chloride diffusion coefficient into mortar. Cem. Concr. Res. 2003, 33, 1021-1028. [CrossRef]

27. Yu, J.; Li, G.Y.; Leung, C.K.Y. Hydration and physical characteristics of ultrahigh-volume fly ash-cement systems with low water/binder ratio. Constr. Build. Mater. 2018, 161, 509-518. [CrossRef]

28. Bijen, J. Benefits of slag and fly ash. Constr. Build. Mater. 1996, 10, 309-314. [CrossRef]

29. Pivonka, P.; Hellmich, C.; Smith, D. Microscopic effects on chloride diffusivity of cement pastes-A scale-transition analysis. Cem. Concr. Res. 2004, 34, 2251-2260. [CrossRef]

30. Mohammed, M.K.; Dawson, A.R.; Thom, N.H. Macro/micro-pore structure characteristics and the chloride penetration of self-compacting concrete incorporating different types of filler and mineral admixture. Constr. Build. Mater. 2014, 72, 83-93. [CrossRef]

31. Nežerka, V.; Bílý, P.; Hrbek, V.; Fládr, J. Impact of silica fume, fly ash, and metakaolin on the thickness and strength of the ITZ in concrete. Cem. Concr. Compos. 2019, 103, 252-262. [CrossRef]

32. Scrivener, K.L.; Nemati, K.M. The percolation of pore space in the cement paste/aggregate interfacial zone of concrete. Cem. Concr. Res. 1996, 26, 35-40. [CrossRef]

33. Zheng, J.J.; Guo, Z.Q.; Huang, X.F.; Stroeven, P.; Sluys, L.J. ITZ volume fraction in concrete with spheroidal aggregate particles and application: Part II, prediction of the chloride diffusivity of concrete. Mag. Concr. Res. 2011, 63, 483-491. [CrossRef]

34. Lu, B.L.; Torquato, S. Nearest-surface distribution functions for polydispersed particle system. Phys. Rev. A 1992, 45, 5530-5544. [CrossRef] [PubMed]

35. Torquato, S. Random Heterogenerous Materials: Microstructure and Macroscopic Properties; Springer: New York, NY, USA, 2001.

36. Qian, C.X.; Ba, M.F.; Guo, X.G.; Han, X.Y. Evaluation of sub-microstructure in concrete with low water-binder ratio by SEM-BSE image analysis. J. Wuhan Univ. Tenol. Mater. Sci. Ed. 2010, 25, 682-686. [CrossRef]

37. Qudoos, A.; Rehman, A.U.; Kim, H.G.; Ryou, J.S. Influence of the surface roughness of crushed natural aggregates on the microhardness of the interfacial transition zone of concrete with mineral admixtures and polymer latex. Constr. Build. Mater. 2018, 168, 946-957. [CrossRef]

38. Branch, J.L.; Epps, R.; Kosson, D.S. The impact of carbonation on bulk and ITZ porosity in microconcrete materials with fly ash replacement. Cem. Concr. Res. 2018, 103, 170-178. [CrossRef]

39. Zheng, J.J.; Li, C.Q.; Zhou, X.Z. Thickness of interfacial transition zone and cement content profiles around aggregates. Mag. Concr. Res. 2005, 57,397-406. [CrossRef]

40. Bentz, D.P. Influence of silica fume on diffusivity in cement-based materials: II, multi-scale modeling of concrete diffusivity. Cem. Concr. Res. 2000, 30, 1121-1129. [CrossRef]

41. Yang, C.C.; Su, J.K. Approximate migration coefficient of interfacial transition zone and the effect of aggregate content on the migration coefficient of mortar. Cem. Concr. Res. 2002, 32, 1559-1565. [CrossRef] 